\title{
Faktor-Faktor yang Memengaruhi Jaminan Kualitas Peralatan di Puskesmas
}

\author{
Factors Affecting Equipment Quality Assurance at Puskesmas
}

\author{
Widianto Pancaharjono ${ }^{1}$, Danny Fajar Mogsa ${ }^{1}$, Armedy Ronny Hasugian ${ }^{1}$, Hadjar Siswantoro ${ }^{1}$, Armadji Kamaludi \\ Syarif $^{1}$, Agus Dwi Harso ${ }^{1}$, Sri Idaiani ${ }^{1}$, Tince Arniati Jovina ${ }^{1}$ \\ 1) Pusat Penelitian dan Pengembangan Sumber Daya dan Pelayanan Kesehatan, Jalan Percetakan Negara No. 29 Jakarta \\ 10560, Indonesia \\ Korespondensi: widiantopancaharjono2@gmail.com
}

Submitted: 13 Mei 2020, Revised: 22 Juli 2020, Accepted: 19 Agustus 2020

https://doi.org/10.22435/jpppk.v4i2.3674

\begin{abstract}
Abstrak
Diperkirakan 40-70\% alat-alat medis di negara-negara miskin dan berkembang mengalami kerusakan, tidak dapat digunakan atau tidak digunakan sesuai tujuannya dan akan memengaruhi kualitas pelayanan kesehatan. Beberapa penelitian menunjukkan masih kurangnya kualitas peralatan di Puskesmas. Tujuan penelitian ini adalah untuk menilai faktor-faktor yang memengaruhi jaminan kualitas alat-alat medis dan nonmedis yang ada di Puskesmas. Penelitian ini merupakan analisis lanjut dari penelitian "Pengembangan Indeks Mutu Pelayanan Kesehatan Puskesmas" pada tahun 2017. Penelitian ini menggunakan desain potong lintang dengan 200 puskesmas terpilih sebagai sampel penelitian. Analisis univariat dilakukan untuk menilai karakteristik responden. Analisis bivariat dilakukan menggunakan uji Chi-square untuk menilai faktor-faktor yang berhubungan dengan jaminan kualitas terhadap peralatan di tempat pelayanan. Variabel yang dianalisis yaitu dilakukan monitoring terhadap pemeliharaan peralatan medis dan nonmedis (p209); ada tempat penyimpanan/gudang sarana dan peralatan yang memenuhi persyaratan (p255); dilakukan kalibrasi atau validasi instrumen/alat ukur tepat waktu dan oleh pihak yang kompeten sesuai prosedur (p820); terdapat bukti dokumentasi dilakukannya kalibrasi atau validasi, dan masih berlaku (p821); ditetapkan kebijakan dan prosedur untuk memisahkan alat yang bersih dan alat yang kotor, alat yang memerlukan sterilisasi, alat yang membutuhkan perawatan lebih lanjut (tidak siap pakai), serta alat-alat yang membutuhkan persyaratan khusus untuk peletakannya (p868) terbukti mempunyai hubungan secara bermakna dan variabel "dilakukan kalibrasi atau validasi instrumen/alat ukur tepat waktu dan oleh pihak yang kompeten sesuai prosedur" berpeluang sebesar 27,681 kali mempunyai jaminan kualitas yang baik terhadap peralatan di tempat pelayanan dibandingkan dengan Puskesmas yang tidak melakukannya.
\end{abstract}

Kata Kunci : Alat kesehatan, sterilisasi, kalibrasi

\begin{abstract}
An estimated $40-70 \%$ of medical equipment in poor and developing countries are damaged, unusable or unused under its purpose and will affect the quality of health services. Several studies have shown that there is still a lack of equipment quality in Puskesmas. The purpose of this study is to assess the factors that affect the quality assurance of medical and non-medical devices in Puskesmas. This study is an in-depth analysis of the "The Development of Puskesmas Health Service Quality Index" in 2017. A cross-sectional design is used with 200 Puskesmas as the research sample. Univariate analysis and Chi-square test were conducted to assess the characteristics of the respondents and the factors associated with quality assurance of equipment at the service center. The analyzed variables are monitoring of medical and non-medical equipment maintenance (p209); storage area/warehouse that meets the requirements (p255); instruments / measuring instruments calibration or validation is carried out on time by competent parties according to procedures (p820); there is
\end{abstract}


still valid documentary evidence of calibration or validation (p821); there is established policies and procedures to use clean and dirty tools, tools requiring sterilization, further treatment and special requirements for their placement (p868) proved to be significant. instruments / measuring instruments calibration or validation is carried out on time by competent parties according to procedures had a 27,681 times chance of having a good quality assurance of equipment in the service place compared to Puskesmas that did not do so.

Keywords: health devices, sterilization, calibration

\section{Pendahuluan}

Pelayanan kesehatan yang berkualitas di fasilitas pelayanan kesehatan membutuhkan jaminan atas perlengkapan sarana prasarana baik medis maupun nonmedis yang berkualitas yang berhubungan dengan kinerja tenaga kesehatan dalam memberikan pelayanan yang optimal bagi masyarakat. Diperkirakan antara $40-70 \%$ peralatan medis di negara-negara miskin dan berkembang mengalami kerusakan, tidak dapat digunakan atau tidak digunakan sesuai tujuannya. ${ }^{1}$ Menurut World Health Organization (WHO), peralatan medis berkontribusi pada pencapaian standar kesehatan tertinggi untuk masyarakat. Karena kurangnya sistem pengaturan untuk perangkat medis di banyak negara, WHO memutuskan untuk mengembangkan dokumen yang dapat memberikan panduan dan dukungan kepada negara-negara anggota WHO mengambil langkah-langkah untuk memastikan kualitas dan keamanan peralatan medis. ${ }^{2}$ Beberapa peraturan perundangan yang diadopsi dari peraturan tersebut adalah Undang Undang (UU) No. 36 Tahun 2009, Peraturan Menteri Kesehatan Republik Indonesia (Permenkes RI) No. 31 Tahun 2018, dan Permenkes RI No. 75 Tahun 2014 yang menyebutkan keharusan tersedianya sarana, prasarana, peralatan kesehatan, dan alat penunjang medik yang aman, bermanfaat, bermutu, laik pakai dan sesuai standar. ${ }^{3-5}$

Kualitas pelayanan kesehatan meliputi empat atribut yaitu keamanan, efektivitas, budaya keunggulan, dan hasil yang diinginkan. Konsep ini digunakan dalam mendefinisikan kualitas peralatan kesehatan, ${ }^{6}$ di mana menurut Permenkes RI No. 54 Tahun 2015 maka alat medis atau peralatan kesehatan adalah "instrumen, aparatus, mesin, perkakas, dan/atau implan, reagen in vitro dan kalibratornya, perangkat lunak, bahan atau material yang digunakan tunggal atau kombinasi, untuk mencegah, mendiagnosis, menyembuhkan, dan meringankan penyakit, merawat orang sakit, memulihkan kesehatan pada manusia, dan/atau membentuk struktur dan memperbaiki fungsi tubuh, menghalangi pembuahan, desinfeksi alat kesehatan, pengujian invitro terhadap spesimen dari tubuh manusia, dapat mengandung obat yang tidak mencapai kerja utama pada tubuh manusia melalui proses farmakologi, imunologi atau metabolisme untuk dapat membantu fungsi/kinerja yang diinginkan". Sementara alat nonmedis adalah alat yang tidak termasuk dalam definisi alat medis. ${ }^{7}$ Namun demikian, keberfungsian ini sering tidak berjalan sebagaimana mestinya.

Berdasarkan hasil Riset Fasilitas Kesehatan (Rifaskes) 2019 ketersediaan peralatan medis dan nonmedis di puskesmas cukup bervariasi dan masih banyak puskesmas yang belum mampu mencapai standar yang ditetapkan atau belum dapat dijamin kualitas dari peralatan kesehatan. Pemanfaatan peralatan yang tersedia juga masih belum maksimal dan beberapa peralatan yang ada tidak berfungsi dengan baik atau tidak dilaporkan fungsinya. ${ }^{8}$ Beberapa penelitian menunjukkan masih kurangnya kualitas peralatan di puskesmas seperti masih terdapat alat kesehatan yang belum berfungsi secara maksimal atau rusak. ${ }^{9}, 10$ Kemudian ditemukan pelaksanaan kegiatan pemeliharaan masih kurang sesuai dengan prosedur, tenaga ahli untuk pemeliharaan alat kesehatan tidak ada, pengetahuan petugas tentang pemeliharaan dan pemanfaatan alat masih kurang, belum memadainya dana untuk biaya pemeliharaan, dan kegiatan pemeliharaan yang masih tidak terencana. ${ }^{11-13,15}$ Selain itu ditemukan kegiatan kalibrasi alat kesehatan antara lain sphygmomanometer aneroid di puskesmas belum berjalan dengan optimal. ${ }^{14,15}$ Beberapa fungsi logistik masih belum maksimal dijalankan, di mana masih dijumpai barang-barang yang tidak disimpan di tempat penyimpanan semestinya. ${ }^{16}$ Dalam hal sterilisasi alat masih terjadi ketidaksiapan personel puskesmas. Beberapa puskesmas belum 
mempunyai Standard Operating Procedure (SOP) untuk pelaksanaan sterilisasi atau petugas masih banyak yang belum mematuhi prosedur, di mana sering tidak melakukan sterilisasi setiap alat yang akan digunakan seperti melakukan tindakan invasif ke pasien walaupun alat sterilisator sebenarnya sudah ada. ${ }^{17}$ Kemudian didapatkan hanya 38,5\% poli gigi di puskesmas melakukan dekontaminasi alat kesehatan, sebanyak $10,3 \%$ poli gigi tidak mempunyai sterilisator yang masih berfungsi dengan baik, 20,5\% tidak melakukan pencucian alat dengan baik setiap kali habis pakai, dan 46,2 $\%$ tidak mempunyai lemari penyimpan alat yang sudah bersih. ${ }^{18}$ Kondisi peralatan nonmedis, seperti komputer dan kendaraan yang meliputi ambulans, pusling maupun kendaraan lainnya masih cukup banyak yang rusak. ${ }^{8}$

Permasalahan diatas muncul akibat tidak adanya kepatuhan terhadap berbagai aturan dan peraturan yang berlaku yang dapat menjamin kualitas peralatan medis dan nonmedis. Berbagai faktor harus dinilai untuk mengetahui, di mana letak masalah atau faktor apa yang tidak dilakukan dalam upaya menjamin kualitas peralatan tida optimal. Oleh karenanya untuk menjaga peralatan medis dan nonmedis puskesmas tetap terjamin kualitasnya diperlukan pemahaman akan faktor-faktor yang memengaruhi jaminan kualitas peralatan tersebut. Dari penjelasan diatas, maka masalah monitoring pemeliharaan, sterilisasi alat, kalibrasi, dan cara penyimpanan bisa menjadi merupakan faktor-faktor yang berhubungan. Tujuan penelitian ini adalah untuk menilai faktor-faktor yang memengaruhi jaminan kualitas alat-alat medis dan nonmedis yang ada di puskesmas.

\section{Metode}

Penelitian ini merupakan analisis lanjut dari penelitian "Pengembangan Indeks Mutu Pelayanan Kesehatan Puskesmas" pada tahun 2017. ${ }^{19}$ Desain penelitian adalah potong lintang. Sampel penelitian sebanyak 200 Puskesmas yang terdiri dari 103 puskesmas terakreditasi dan 97 tidak terakreditasi yang tersebar di 27 kabupaten/kota di 10 provinsi di Indonesia. Variabel dependen dalam penelitian ini adalah adanya jaminan kualitas terhadap peralatan di tempat pelayanan kesehatan (puskesmas) (p740). Variabel independen meliputi: dilakukan monitoring terhadap pemeliharaan peralatan medis dan nonmedis (p209); ada tempat penyimpanan/ gudang sarana dan peralatan yang memenuhi persyaratan (p255); dilakukan kalibrasi atau validasi instrumen/alat ukur tepat waktu dan oleh pihak yang kompeten sesuai prosedur (p820); terdapat bukti dokumentasi dilakukannya kalibrasi atau validasi, dan masih berlaku (p821); ditetapkan kebijakan dan prosedur untuk memisahkan alat yang bersih dan alat yang kotor, alat yang memerlukan sterilisasi, alat yang membutuhkan perawatan lebih lanjut (tidak siap pakai), serta alat-alat yang membutuhkan persyaratan khusus untuk peletakannya (p868).

Pengumpulan data dilakukan dengan cara telusur kelengkapan dokumen bukti dan atau pengamatan dan atau simulasi dan atau wawancara petugas dan memberikan skor pada masing-masing elemen penilaian sebesar 0,5 atau 10 di puskesmas penelitian oleh tim peneliti terlatih. Telusur kelengkapan dokumen untuk menilai ketersediaan dokumen regulasi, buktibukti pertemuan (undangan, absensi, notulen, dan gambar/foto); pengamatan dilakukan untuk menilai perilaku petugas, ketersediaan sarana, prasarana dan alat kesehatan; simulasi dan wawancara petugas dilakukan untuk menilai pemahaman petugas terhadap prosedur-prosedur kegiatan. ${ }^{19} \mathrm{Cara}$ pengukuran semua variabel dengan menggunakan skala $0(<20 \%), 5(20-79 \%)$, dan $10(80-100 \%) .{ }^{20}$ Pengelompokan dilakukan untuk analisis dengan membagi skala menjadi dua yaitu $0-5$ disebut tidak terpenuhi, 10 disebut terpenuhi. Untuk mengatasi kurangnya skor pada kelompok 0 dilakukan penggabungan sehingga data dapat dianalisis lebih optimal. Analisis univariat dilakukan untuk menilai karakteristik sampel penelitian. Analisis bivariat dilakukan menggunakan uji chi-square untuk menilai faktor-faktor yang berhubungan dengan jaminan kualitas terhadap peralatan di tempat pelayanan. Data dianalisis menggunakan software SPSS.

\section{Hasil}

Berdasarkan analisis univariat terdapat total 200 puskesmas yang diambil sebagai sampel yang terdiri dari 103 puskesmas terakreditasi dan 97 puskesmas belum terakreditasi. Sampel tersebut tersebar di 27 kabupaten/kota di 10 propinsi di 
Indonesia dengan mayoritas sampel terdapat di Pulau Jawa. Hal ini didasarkan pada pembagian sampel yang dilakukan dalam pengembangan desain penelitian dari protokol utama.

Dari Tabel 1 secara keseluruhan jumlah yang keterpenuhan (skor 10) dengan yang tidak keterpenuhan (skor 0 dan 5) cukup berimbang. Tampak bahwa secara umum seluruh elemen penilaian sudah dipenuhi oleh sebagian besar puskesmas (skor 10) terbanyak pada p820 sedangkan terendah pada $\mathrm{p} 255$. Skor 0 terbanyak ada pada $\mathrm{p} 821$ sedangkan terendah pada p255.

Berdasarkan Tabel 2 didapatkan bahwa kelima variabel memiliki hubungan bermakna terhadap jaminan kualitas terhadap peralatan di tempat pelayanan (p740). Dari kelima variabel tersebut, p820 mempunyai peluang sebesar 27,681 kali mempunyai jaminan kualitas yang baik terhadap peralatan di tempat pelayanan dibandingkan dengan puskesmas yang tidak melakukan.

Tabel 1. Distribusi Skor Elemen Penilaian Terkait dengan Jaminan Kualitas terhadap Peralatan di Tempat Pelayanan Kesehatan (Puskesmas)

\begin{tabular}{rrrrrrrrrrrrr}
\hline \multirow{2}{*}{ Skor } & \multicolumn{10}{c}{ Jumlah Skor Elemen Penilaian } \\
\cline { 2 - 12 } & $\mathbf{p 7 4 0}$ & \% & $\mathbf{p 2 0 9}$ & $\mathbf{\%}$ & $\mathbf{p 2 5 5}$ & $\mathbf{\%}$ & $\mathbf{p 8 2 0}$ & $\mathbf{\%}$ & $\mathbf{p 8 2 1}$ & $\mathbf{\%}$ & $\mathbf{p 8 6 8}$ & $\mathbf{\%}$ \\
\hline 0 & 33 & 16,5 & 58 & 29,0 & 23 & 11,5 & 55 & 27,5 & 63 & 31,5 & 47 & 23,5 \\
5 & 45 & 22,5 & 36 & 18,0 & 74 & 37,0 & 20 & 10,0 & 26 & 13,0 & 41 & 20,5 \\
10 & 122 & 61,0 & 106 & 53,0 & 103 & 51,5 & 125 & 62,5 & 111 & 55,5 & 112 & 56,0 \\
\hline
\end{tabular}

Tabel 2. Distribusi Faktor-faktor yang Berhubungan dengan Jaminan Kualitas terhadap Peralatan di Tempat Pelayanan (Puskesmas)

\begin{tabular}{cccccccr}
\hline \multirow{2}{*}{$\begin{array}{c}\text { Elemen } \\
\text { Penilaian }\end{array}$} & \multicolumn{9}{c}{$\mathbf{p 7 4 0}$} & P & OR \\
\cline { 2 - 6 } & Terpenuhi & \multicolumn{1}{c}{$\mathbf{n}$} & Tidak Terpenuhi & $\mathbf{n}$ & $\mathbf{N}$ & & 8,627 \\
p209 & $83,00 \%$ & 88 & $17,00 \%$ & 18 & 106 & 0,000 & 3,758 \\
p255 & $75,70 \%$ & 78 & $24,30 \%$ & 25 & 103 & 0,000 & 27,681 \\
p820 & $86,40 \%$ & 108 & $13,60 \%$ & 17 & 125 & 0,000 & 10,69 \\
p821 & $83,80 \%$ & 93 & $16,20 \%$ & 18 & 111 & 0,000 & 16,296 \\
p868 & $86,60 \%$ & 97 & $13,40 \%$ & 15 & 112 & 0,000 & \\
\hline
\end{tabular}

\section{Pembahasan}

Jaminan kualitas terhadap peralatan di tempat pelayanan kesehatan dipengaruhi oleh pelaksanaan standar operasional dan validasi terhadap semua peralatan medis dan nonmedis. Dari hasil analisis yang tampak pada Tabel 2 menunjukkan bahwa p820 (dilakukannya kalibrasi atau validasi instrument/alat ukur tepat waktu dan oleh pihak yang kompeten sesuai prosedur) mempunyai OR paling tinggi yaitu 27,681 menunjukkan variabel ini merupakan faktor prediksi terkuat daripada faktor-faktor yang lain. Penelitian Altayyar Saleh tahun 2018 yang meneliti sampel representatif $20,5 \%$ dari total aset (1034) menunjukkan bahwa $34 \%$ dari sampel gagal dalam tes visual, $5 \%$ gagal dalam tes keamanan, dan $58 \%$ gagal dalam tes kinerja. Walaupun tidak ada kematian atau insiden serius yang terkait dengan alat-alat ini namun terbukti alat tidak memenuhi standar internasional dan penggunaan yang berkelanjutan dari perangkat tersebut dapat membahayakan keselamatan pasien. ${ }^{21}$

Selain itu, de Greeffb A dalam penelitiannya merekomendasikan bahwa penilaian kalibrasi rutin sphygmomanometer dilakukan untuk memastikan bahwa perangkat sesuai dengan spesifikasi standar. Diperkirakan bahwa kesalahan kalibrasi dapat mengakibatkan satu dari lima pasien hipertensi tidak didiagnosis dan sebaliknya hampir sepertiga dari pasien salah didiagnosis dengan hipertensi. ${ }^{15}$ Puskesmas harus berupaya untuk mengurangi biaya perawatan kesehatan tanpa mengurangi kualitas perawatan kesehatan dan diagnosis medis yang 
tepat. Mereka menjadi lebih sadar akan pentingnya kalibrasi perangkat medis dan dampaknya pada kualitas layanan kesehatan yang diberikan kepada pasien, dan keselamatan pasien. ${ }^{21}$

Indonesia sudah memiliki regulasi tersendiri mengenai pengujian dan kalibrasi alat kesehatan yaitu Permenkes RI No 54 Tahun 2015. Pengaturan Pengujian dan Kalibrasi Alat Kesehatan bertujuan untuk memberikan acuan bagi pemerintah, pemerintah daerah dan masyarakat dalam pelaksanaan pengujian dan/atau kalibrasi alat kesehatan, menjamin tersedianya alat kesehatan yang sesuai standar pelayanan, persyaratan mutu, keamanan, manfaat, keselamatan dan laik pakai di Fasilitas Pelayanan Kesehatan dan Fasilitas Kesehatan lainnya, meningkatkan akuntabilitas, dan mutu pelayanan Balai Pengujian Fasilitas Kesehatan dan Institusi Pengujian Fasilitas Kesehatan dalam pengujian dan/atau kalibrasi alat kesehatan. ${ }^{7}$ Walaupun regulasi sudah ada dan pedoman pelaksanaan sudah dibuat, pelaksanan kalibrasi peralatan di puskesmas masih belum dilaksanakan secara optimal. OMBUDSMAN menyebutkan bahwa kurangnya sosialisasi, terbatasnya distribusi personil dan jumlah laboratorium kalibrasi yang memenuhi syarat, tidak terpenuhinya anggaran pemeliharaan dan kalibrasi alat kesehatan, menyebabkan upaya kegiatan pemeliharaan dan kalibrasi pada sejumlah alat kesehatan yang ada di sarana pelayanan kesehatan baik pemerintah maupun swasta termasuk puskesmas sulit untuk dilakukan. ${ }^{22}$ Untuk menjamin kualitas laboratorium pengujian, kriteria umum penyelenggaraan dan persyaratanpersyaratan umum kompetensi laboratorium pengujian dan kalibrasi harus dimasukkan dalam model sistem kualitas laboratorium. ${ }^{23}$

Selain dilakukannya kalibrasi peralatan, jaminan kualitas peralatan medis dan nonmedis juga dipengaruhi oleh faktor ditetapkannya kebijakan dan prosedur untuk memisahkan alat yang bersih dan alat yang kotor, alat yang memerlukan sterilisasi, alat yang membutuhkan perawatan lebih lanjut (tidak siap pakai), serta alat-alat yang membutuhkan persyaratan khusus untuk peletakannya. Hal ini seiring dengan hasil penelitian yang menyatakan bahwa kondisi alat yang terdisinfeksi dan tersterilisasi merupakan kegiatan yang penting untuk memastikan bahwa peralatan medis dan bedah tidak menjadi perantara penularan infeksi patogen kepada pasien. ${ }^{24}$ Secara global, ratusan juta orang terkena dampak setiap tahun oleh infeksi yang diperoleh dari perawatan kesehatan yang seharusnya dapat dihindari (Healthcare-Associated Infections (HAIs)/ infeksi nosokomial). Sterilisasi dan dekontaminasi instrumen dan peralatan medis memainkan peran yang sangat penting dalam pencegahan HAIs. Di banyak tempat dengan sumber daya rendah penggunaan kembali yang tidak tepat dari perangkat medis sekali pakai merupakan praktik umum sementara prosedur untuk membersihkan dan mendekontaminasi perangkat ini tidak memadai dan tidak sesuai standar. Proses sterilisasi dan dekontaminasi merupakan proses yang rumit, membutuhkan infrastruktur dan peralatan spesifik serta melibatkan beberapa langkah yang harus benar, dari pengumpulan perangkat, penerimaan oleh unit, pemrosesan, penyimpanan, dan distribusi ke seluruh fasilitas. ${ }^{25}$ Pemerintah Indonesia melalui Permenkes RI No. 27 Tahun 2017 tentang Pedoman Pencegahan dan Pengendalian Infeksi di Fasilitas Pelayanan Kesehatan memberikan pedoman yang cukup jelas bagaimana kegiatan sterilisasi dan disinfeksi di fasilitas kesehatan yaitu rumah sakit, puskesmas, klinik, dan praktik mandiri harus dilaksanakan. ${ }^{26}$ Walaupun sudah ada pedoman baku mengenai pencegahan infeksi di tempat pelayanan kesehatan masih tetap ada gap antara regulasi dengan pelaksanaan di lapangan. Kurang baiknya kegiatan disinfeksi dan sterilisasi sehingga menyebabkan infeksi dapat disebabkan baik oleh karena kegagalan dalam mengikuti pedoman yang berbasis ilmiah maupun kegagalan dalam pelaksanaan proses disinfeksi dan sterilisasi. ${ }^{27}$

Dari hasil penelitian ini menunjukkan bahwa adanya jaminan kualitas peralatan di tempat pelayanan kesehatan juga dipengaruhi oleh faktor pelaksanaan monitoring terhadap pemeliharaan peralatan medis dan nonmedis. Berdasarkan penelitian Dwiastuti tahun 2012 dengan adanya monitoring pemeliharaan peralatan kesehatan, kegiatan pemeliharaan peralatan kesehatan terjadwal dengan baik sehingga dapat lebih efektif dan dapat meminimalisir terlewatinya kegiatan pemeliharaan dan memberikan output dalam bentuk kesimpulan kondisi alat berdasarkan data hasil pemeliharaan selama monitoring. ${ }^{28}$ Proses pemeliharaan 
merupakan fungsi inti dari kegiatan klinis, yang memiliki tujuan untuk menjamin keamanan dan kualitas perangkat medis dan investasi dalam peralatan melalui peningkatan keawetan barang. Agar peralatan kesehatan selalu dalam kondisi siap dan laik pakai maka kegiatan pemeliharaan mutlak dilaksanakan secara terus-menerus sehingga perlu disusun prosedur pemeliharaan yang baku. ${ }^{29,30}$ Proses pemeliharaan termasuk di dalamnya adalah penentuan peralatan yang tidak bisa digunakan lagi dan penggantian yang terus-menerus dan sistematis dengan cara dan pada waktu yang tepat, servis berkala dan deteksi kebutuhan untuk servis atau penggantian besar akan mempertahankan kinerja, pencegahan karena kesalahan kinerja atau kegagalan alat, pengurangan biaya perbaikan, dan pencegahan peralatan menjadi berbahaya. Peralatan yang tidak dapat diandalkan atau usang tetapi tetap digunakan menempatkan pasien dan pengguna dalam risiko. Dalam beberapa kasus, kegagalan satu perangkat dapat memicu kegagalan perangkat lain yang akan memperbesar konsekuensi dan biaya..$^{30,31}$ Pemeliharaan peralatan berdampak signifikan pada pendapatan dan secara tidak langsung memengaruhi vitalitas tempat pelayanan kesehatan. Untuk alasan ini, bagian pemeliharaan memerlukan pengawasan yang cermat oleh manajemen tempat pelayanan kesehatan, tetapi banyak di antaranya mungkin tidak memiliki latar belakang teknis untuk memahami semua faktor yang relevan sehingga diperlukan SDM yang handal di bidang ini. ${ }^{31}$ Mengadopsi model perawatan untuk meminimalkan risiko dan mengoptimalkan efektivitas biaya peralatan medis dari pedoman negara lain atau negara maju tidak menunjukkan kinerja keseluruhan yang membaik dan efektif dalam hal manajemen risiko dan biaya program pemeliharaan. Oleh karena itu, model yang diusulkan perlu dimodifikasi agar sesuai dengan tempat pelayanan kesehatan di negara tersebut. ${ }^{32}$ Beberapa penelitian merekomendasikan penggunaan software tertentu untuk sistem pemeliharaan peralatan di tempat pelayanan kesehatan. Dengan mengukur parameter input dan pemantauan terus menerus terhadap parameter-parameter output menunjukkan peningkatan yang terjadi dalam sistem. ${ }^{33}$

Adanya jaminan kualitas terhadap peralatan di tempat pelayanan juga dipengaruhi secara signifikan oleh adanya tempat penyimpanan/gudang sarana dan peralatan yang memenuhi persyaratan. Hal ini sejalan dengan penelitian Mingzhou Jin yang menyajikan studi kasus penerapan prinsip-prinsip dan prosedur Six Sigma dan Lean Thinking dalam merancang dan mengoperasikan pusat logistik kesehatan. Proyek ini menghasilkan manajemen penyimpanan yang lebih baik. ${ }^{34}$ Permenkes RI No. 30 tahun 2014 tentang Standar Pelayanan Kefarmasian di Puskesmas menyebutkan bahwa penyimpanan obat dan bahan medis habis pakai merupakan suatu kegiatan pengaturan terhadap obat dan bahan medis habis pakai yang diterima agar aman (tidak hilang), terhindar dari kerusakan fisik maupun kimia, dan mutunya tetap terjamin sesuai dengan persyaratan yang ditetapkan. Tujuannya adalah agar mutu yang tersedia di puskesmas dapat dipertahankan sesuai dengan persyaratan yang ditetapkan. ${ }^{35}$ Data Rifaskes 2019 menunjukkan bahwa puskesmas di Indonesia yang mempunyai gudang umum sudah cukup banyak yaitu sebesar $72,3 \%$ mempunyai ruang tersendiri, $4,3 \%$ bergabung dengan ruangan lain, 23,4\% belum mempunyai. Kondisi ruangan gudang $77,3 \%$ cukup baik, $19,4 \%$ kurang baik, dan $3,3 \%$ tidak baik. ${ }^{8}$

Dari penelitian ini secara umum terlihat bahwa monitoring pemeliharaan, prosedur sterilisasi, kalibrasi berkala, dan prosedur penyimpanan alatalat medis maupun nonmedis sudah terlaksana dengan baik, tetapi masih ditemukan faktor-faktor yang belum dilakukan dengan optimal.

Sementara itu, dari hasil penelitianpenelitian yang lain, kendala yang terutama disebabkan kurangnya SDM, anggaran untuk biaya pemeliharaan belum cukup, kurangnya pengetahuan dan keterampilan petugas, minimnya sosialisasi, minimnya jumlah laboratorium kalibrasi yang memenuhi syarat, perencanaan masih kurang maksimal, dan belum adanya protap (prosedur kerja tetap) untuk pelaksanaan. ${ }^{11-18}$ Dengan diketahuinya signifikansi faktor-faktor yang memengaruhi jaminan kualitas peralatan di puskesmas ini berimplikasi pada perlunya pemecahan pada permasalahan-permasalahan yang menjadi penyebab masih kurangnya pelaksanaannya di puskesmas baik dari segi peraturan, pedoman, ketersediaan laboratorium kalibrasi, SOP, pendanaan, dan sumber daya manusia. 
Penelitian ini merupakan penelitian potong lintang sehingga tidak bisa menyatakan hubungan sebab akibat namun demikian dari hasil penelitian didapatkan variabel independen mempunyai hubungan yang bermakna dengan variabel dependen. Sampel yang digunakan merujuk pada penelitian terkait akreditasi sehingga menjadi terbatas namun tetap dapat menunjukkan hasil yang menjawab tujuan penelitian. Untuk mengatasi kurangnya skor pada kelompok 0 dilakukan penggabungan sehingga data dapat dianalisis lebih optimal

\section{Kesimpulan}

Faktor-faktor yang berhubungan dengan jaminan kualitas terhadap peralatan di tempat pelayanan kesehatan (puskesmas) adalah: dilakukan monitoring terhadap pemeliharaan peralatan medis dan nonmedis; ada tempat penyimpanan/gudang sarana dan peralatan yang memenuhi persyaratan; dilakukan kalibrasi atau validasi instrumen/alat ukur tepat waktu dan oleh pihak yang kompeten sesuai prosedur; terdapat bukti dokumentasi dilakukannya kalibrasi atau validasi, dan masih berlaku; ditetapkan kebijakan dan prosedur untuk memisahkan alat yang bersih dan alat yang kotor, alat yang memerlukan sterilisasi, alat yang membutuhkan perawatan lebih lanjut (tidak siap pakai), serta alatalat yang membutuhkan persyaratan khusus untuk peletakannya.

\section{Saran}

Diperlukan pemecahan pada permasalahanpermasalahan yang menjadi penyebab masih kurangnya pelaksanaan faktor-faktor yang memengaruhi jaminan kualitas peralatan di puskesmas. Perlunya regulasi dan pedoman pelaksanaan yang tepat berbasis ilmiah sehingga selalu sesuai perkembangan ilmu dan teknologi. Peraturan dan pedoman yang sudah ada perlu diperbaiki baik dalam hal isi maupun penegakannya di lapangan. Puskesmas perlu semakin meningkatkan perencanaan dan pelaksanaan faktor-faktor yang memengaruhi jaminan kualitas peralatan tersebut dengan lebih serius dan penuh tanggung jawab sehingga dapat mencapai mutu pelayanan kesehatan yang maksimal. Adanya SOP yang jelas, dipahami dan dilaksanakan oleh semua petugas serta monitoring dan evaluasi secara berkala oleh kepala puskesmas. Bagi para pemegang kebijakan perlu untuk mempertimbangkan sistem penganggaran yang lebih menunjang terlaksananya programprogram yang berkaitan dengan faktor-faktor tersebut serta pemenuhan dan pendistribusian sumber daya manusia yang terlatih. Di samping itu, berdasarkan pernyataan OMBUDSMAN bahwa ada keterbatasan distribusi personel dan jumlah laboratorium kalibrasi yang memenuhi syarat, maka pemerintah perlu mengkaji kebutuhan akan jumlah personel dan laboratorium kalibrasi yang memenuhi syarat dan mencukupi kekurangan yang ada. ${ }^{22}$

\section{Kontribusi Penulis}

WP, DFM melakukan pengumpulan data, pengolahan data dan pembuatan draft artikel. HS, AKS, ADH melakukan pengumpulan data dan menambahkan pengolahan data. ARH menambahkan pengolahan data dan pembahasan. SI dan TAJ menambahkan dibagian refrensi dan pembahasan. Seluruh penulis membaca dan menyetujui artikel ini.

\section{Ucapan Terima Kasih}

Terima kasih kami sampaikan kepada Kepala Pusat Penelitian dan Pengembangan Sumber Daya dan Pelayanan Kesehatan Badan Litbangkes, Kepala Bidang Pelayanan Kesahatan dan Kepala Sub. Bidang Yankes Tradisional dan Penunjang, serta kepada semua pihak yang membantu pembuatan artikel ini yang tidak dapat kami sebutkan satu persatu.

\section{Daftar Pustaka}

1. Perry L, Malkin R. Effectiveness of medical equipment donations to improve health systems: how much medical equipment is broken in the developing world?. Med Biol Eng Comput. 2011;49(7):719-22. doi:10.1007/s11517-0110786-3

2. World Health Organization (WHO). WHO Global Model Regulatory Framework for Medical Devices Including in Vitro Diagnostic Medical Devices. WHO technical report series; No. 1003. Geneva: the WHO Document Production Services; 2017. 76 p.

3. Indonesia. Undang-Undang No. 36 Tahun 2009 
tentang Kesehatan.

4. Indonesia, Kementerian Kesehatan. Peraturan Menteri Kesehatan RI No. 31 Tahun 2018 tentang Aplikasi Sarana, Prasarana, dan Alat Kesehatan.

5. Indonesia, Kementerian Kesehatan. Peraturan Menteri Kesehatan RI No. 75 Tahun 2014 tentang Pusat Kesehatan Masyarakat.

6. Allen-Duck A, Robinson JC, Stewart MW. Healthcare Quality: A Concept Analysis. Nurs Forum. 2017;52(4):377-86. doi:10.1111/ nuf. 12207

7. Indonesia, Kementerian Kesehatan. Peraturan Menteri Kesehatan RINo.54 Tahun 2015 tentang Pengujian dan Kalibrasi Alat Kesehatan.

8. Indonesia, Badan Penelitian Dan Pengembangan Kesehatan (Balitbangkes) Kementerian Kesehatan Republik Indonesia. Laporan Riset Fasilitas Kesehatan 2019. Jakarta:Lembaga Penerbit Balitbangkes; 2019.

9. Fannya P. Evaluasi Pelaksanaan Manajemen Logistik Alat Kesehatan di Puskesmas Biaro Kabupaten Agam Tahun 2010. [Skripsi].Sumatra Barat: Fakultas Kedokteran Universitas Andalas Padang.2011.

10. Valentina A, Suparwati A, Suryoputro A. Analisis Pelaksanaan Sistem Pelayanan Obstetri dan Neonatal Emergensi Dasar (PONED) di Puskesmas Sitanggal Kabupaten Brebes. J Kesehat Masy Univ Diponegoro. 2016;4(4):154-61.

11. Yolli E. Analisis Sistem Pemeliharaan Peralatan Medis di Puskesmas Seberang Padang Kota Padang Tahun 2015. [Skripsi]. Sumatra Barat: Universitas Andalas Padang; 2015.

12. Hendrayani A. Pengaruh Pendampingan Inspeksi Perawatan Pencegahan (Preventif Maintenance ) Alat Elektrokardiografi. J Penelit Kesehat Suara Forikes. 2017;8(1):1-6.

13. Angkasawati TJ, Arifin A, Astuti WD, Turniani. Laporan Akhir Penelitian Kajian Pemanfaatan dan Pemeliharaan Sarana dan Alat Kesehatan di Rumah Sakit dan Puskesmas. Jakarta: Badan Litbangkes Kemenkes; 2005.

14. Irawati N, Purwadi D, Mathori M. Upaya Peningkatan Kinerja Pelaksanaan Program Pemeliharaan dan Kalibrasi Alat Kesehatan Puskesmas di Dinas Kesehatan Kabupaten
Pacitan. [Tesis]. Yogyakarta: Program Magister Manajemen Sekolah Tinggi Ilmu Ekonomi Widya Wiwaha; 2018.

15. de Greeff A, Lorde I, Wilton A, Seed P, Coleman AJ, Shennan AH. Calibration accuracy of hospital-based non-invasive blood pressure measuring devices. J Hum Hypertens. 2010;24(1):58-63. doi:10.1038/jhh.2009.29

16. Ramadhan F. Analisis Manajemen Logistik Alat Kesehatan di Puskesmas Boja II Kabupaten Kendal Tahun 2018. [Skripsi]. Universitas Negeri Semarang; 2019.

17. Angkasawati T, Arifin A. Kesiapan Petugas Puskesmas dalam Penanggulangan Infeksi Menular Seksual dan HIV/AIDS pada Pelayanan Antenatal. Bul Penelit Sist Kesehat. 2009;12(4):403-8.

18. Handayani FT, Widodo AHB. Universal Precaution of Dental Health Service at Public Health Center in The Entire Banyumas Regency. J Kesmas Indones. 2010;3(1):47-55.

19. Siswantoro H, Siswoyo H, Nurhayati, Tie D, Afrilia AR, Harso AD, et al. Pengembangan Indeks Mutu Pelayanan Kesehatan Puskesmas. MediaLitbangkes .2019;29(3):269-283. doi:10.22435/mpk.v29i3.1156

20. Indonesia, Kementerian Kesehatan. Peraturan Menteri Kesehatan RI No. 46 Tahun 2015 tentang Akreditasi Puskesmas, Klinik Pratama, Tempat Praktik Mandiri Dokter dan Dokter Gigi.

21. Altayyar SS, Mousa MA, Alfaifi AM, Negm AE, Ali MO. The Impact of Calibration on Medical Devices Performance and Patient Safety. Biomed Res. 2018;29(12):2553-60.

22. Susana E, Nursyamsi I, Kristianti W, Komarudin A. Gerakan Sakamed sebagai Upaya Meningkatkan Kesadaran Pentingnya Kalibrasi Alat Kesehatan di Puskesmas. Din J Pengabdi Kpd Masy. 2020;4(2):346-53.

23. Berte LM, Nevalainen DE, Peters HJ. A Quality System for The Medical Laboratory. J Lab Med. 1997;21(1):44-50.

24. Rutala WA, Weber DJ. Disinfection and Sterilization in Health Care Facilities: An Overview and Current Issues. Infect Dis Clin North Am. 2016;30(3):609-37. doi:10.1016/j. idc.2016.04.002 
25. World Health Organization and Pan American Health Organization. Decontamination and Reprocessing of Medical Devices for Healthcare Facilities. WHO. Geneva: WHO Press; 2016. 1-118 p.

26. Indonesia, Kementerian Kesehatan. Peraturan Menteri Kesehatan RINo. 27 Tahun 2017 tentang Pedoman Pencegahan dan Pengendalian Infeksi di Fasilitas Pelayanan Kesehatan. Permenkes Indonesia.

27. Weber DJ, Rutala WA. Assessing the risk of disease transmission to patients when there is a failure to follow recommended disinfection and sterilization guidelines. Am J Infect Control. 2013;41(5 SUPPL.):146-55. doi:10.1016/j. ajic.2012.10.031

28. Dwiastuti R, Andayani DH. Sistem Monitoring Pemeliharaan Peralatan Kesehatan Berbasis Software Di Rsj Dr. Radjiman Wediodiningrat Lawang. Jurnal Teknokes. 2012;7(1):549-58.

29. Indonesia, Ditjen Pelayanan Medik Departemen Kesehatan dan Kesejahteraan Sosial. Pedoman Operasional dan Pemeliharaan Peralatan Kesehatan (The Technical SOP and SMP of Medical Equipment) (sebagai Panduan Menyusun Protap Pengoperasian dan Protap Pemeliharaan Peralatan Kesehatan). Jakarta; 2001.
30. Hyman WA. The Theory and Practice of Preventive Maintenance. $J$ Clin Eng. 2003;28(1):31-6. doi:10.1097/00004669200301000-00037

31. Wang B. Medical Equipment Maintenance: Management and Oversight Synthesis Lectures on Biomedical Engineering. Connecticut: Morgan \& ClaypoolPublishers;2012.1-83p.doi: 10.2200/S00450ED1V01Y201209BME045

32. KhalafABs. Maintenance Model for Minimizing Risk and Optimizing Cost-effectiveness of Medical Equipment in Palestine. J Clin Eng. 2004;29(4):210-7.

33. Medhat N, Samy SA, Wahed MA, Mohamed ASA. Medical Equipment Quality Assurance for Healthcare Facilities. 2008 Cairo International Biomedical Engineering Conference, Cairo; 2008:1-4. doi:10.1109/CIBEC.2008.4786101

34. Jin M, Switzer M, Agirbas G. Six Sigma and Lean in healthcare logistics centre design and operation: a case at North Mississippi Health Services. Int J Six Sigma Compet Advant. 2008;4(3):270-88. doi:10.1504/ IJSSCA.2008.02184

35. Indonesia, Kementerian Kesehatan. Peraturan Menteri Kesehatan RI No. 30 Tahun 2014 tentang Standar Pelayanan Kefarmasian di Puskesmas. 